account other than in the Japanese language and the wide representation of the Japanese flora in the gardens and herbaria of the world have long made it desirable. Very short introductory phytogeographic and historical reviews of Japanese botany are followed by a standard floristic account of the Pteridophyta (arranged by Copeland's system), Monocotyledones and Dicotyledones, arranged by the Englerian system. Keys to and descriptions of families, genera and species are given, as is a selected synonymy, but, unfortunately, no complete synonymy, no biblio. graphic references and no typifications. The work closes with useful provincial and prefectural maps of Japan, a reference list of authors' names, dates, countries and specialities, and indices to (romanized) Japanese and scientific plant names.

The flora is but poorly illustrated with only seventeen black-and-white plates and seventeen line-drawings, though these few that aro included are of excellent quality. As there have recently been produced some fine series of coloured illustrations of Japanese plants, cross-references to these at least would have done something to offset this deficiency, and help the user to identify his plants. Because this book does not present the information re. quired to bring it into the category of a critical regional flora, it must be judged as a manual for identification, and the final verdict must be left to the user. That it is, in effect, a third edition of two Japanese versions of 1953 and 1957 (and sister of the 1965 Japanese edition) means this English edition at least contains keys that have had the opportunity of roceiving any necessary corrections that usage might have required. This being so it is unfortunate that something has gone very wrong with the key to the genera of Compositae so that it is barely possible to determine correctly genera 29-37 inclusive using it.

'Taxonomically, the work suffers from the endemic discase of local floras which are not backed by sufficiently wide monographic studies-a tendency towards parochialism in the circumscription of genera and the maintenance of what can at best be considered as but doubtful species. Nevertheless, this book is welcome in that it makes available in one place to the English reading public much previously scattered and more or less in. accessible information on one of the best known floras of Asia. Japanese botanists have cause to congratulate themselves that their flora merits this description; but perhaps they can now leave it alone for a bit, and concentrate their efforts on wide-ranging family and generic monographs and revisions-the sore need of taxonomic botany today.

C. JFFFREY

\section{Size and Cycle}

An Essay on the Structure of Biology. By John Tyler Bonner. Pp. viii $+219+30$ plates. (Princeton, N.J.: Princeton University Press; London: Oxford University Press, 1965.) 60s. net.

This essay treats cells and whole organisms as units which pass through cycles of activity, growth, differentiation and reproduction; its aim is to establish a framework within which topics as diverse as the growth rate of an individual amocba, the timing of diurnal activity by a flying fox, and the alternation of generations in plants can be assembled and compared. The aim is therefore taxonomic, and Bonner has no strong thesis to argue; the reader will not find here the fire of the enthusiast. Evolution necessarily enters into the discussion, and one notices how much enthusiasts have tended to concentrate here. My hope is that students will bo led back from this mild and scholarly volume to the fighting works of Garstang, Darlington and Sonneborn. Discussions of mechanism are largely avoided; perhaps wisely. The "rate-controlling" genos that would have figured so largely in a similar discussion twenty years ago now sound a little old-fash. ioned. On the other hand, it is a pity to find no discussion, in a work of such wide range, of the sequence of events in bacteriophage development, or of enzyme syntheses in yeast. Perhaps the attitude of scepticism towards micro-organism "models" that prevails among students of development is responsible for the limits set here.

With these minor reservations, I recommend this useful guide to the literature.

N. A. Mitchison

\section{High Energy Physics}

Edited by Gyo Takeda. (1965 Tokyo Summer Lectures in Theoretical Physics, Part 2.) Pp. iv + 121. (Tokyo: Syokabo; Now York: W. A. Benjamin, Inc., 1966.) $\$ 6.35$.

THIs small volume of lecture notes by eight distinguished theoretical physicists is an excellent survey of recent developments in the physics of elementary particles. This is not an introductory book, but it is suitable for graduate students who have already studied at research level for 1 or 2 years, and would also be valuable to most senior research physicists in this field.

The book includes a general survey by $G$. F. Chew of (a) Regge theory and the $S$ matrix, and $(b)$ bootstraps. L. Van Hove and T. Kinoshita discuss the general theoretical properties of scattering amplitudes at high energy. R. E. Marshak contributes a survey of the present status of weak interactions, and there are valuable discussions about different aspects of symmetries by $\mathrm{Y}$. Ne'eman, Y. Nambu, S. A. Bludman and S. L. Glashow.

\section{R. J. EDEN}

\section{Advances in Marine Biology}

Vol. 3. Fdited by Frederick S. Russell. Pp. $x+402$. (London: Academic Press, Inc. (London), Ltd.; New York: Academic Press, Inc., 1965.) 84s.

Althovgh containing only four reviews, this volume continuos the wide coverage of its predecessors. What indeed could be more diverse than learning in marine invertebrates, the effects of heated effluents on marine and ostuarine organisms, aspects of the biology of seaweeds of economic importance, and marine toxins and venomous and poisonous marine animals? Yet all are indubitably within the range of marine biology.

M. J. Wells comes very well prepared to a consideration of the first of these subjects; his major contributions to the study of behaviour in Cophalopoda following and then accompanying those of J. Z. Young are admirably summarized. A critical review of work on polychaetes, crustaceans (and Limulus), gastropod and bivalve Mollusca, Platyhelminthes, Echinodermata and Coslenterata follows. While "most animals can be shown to learn something sometime", the only successful experiments are those which, by accident or design, "mimic some natural learning situation".

Heated effluents, the effects of which are reviewed by E. Naylor, are a consequence of the use of cooling water in electricity generating stations, and as these proliferate their effect grows. By changing the local environment they represent large scalo exprriments in nature and also present interesting economic possibilities.

In a most thorough survey-containing twenty-six pages of references-A. D. Boney deals with the world wide question of economically valuable seaweeds Nowhere has the value of "pure" research been better illustrated than in the work of K. M. Drew on the Conchocelis -phase of Porphyra which provided knowledge which led to the revival of a most important Japanese culture.

Venomous marine animals may cause severe injury; no less suffering may be caused by consumption of the flesh of poisonous ones. Findlay E. Russell deals with the enormous range of marine organisms which display one or other of these properties, ranging from dinoflagellates to fishes and covering every aspect of the subject. Work in this field has increased greatly over recent years and we are most fortunate in having it so well reviewed.
C. M. Yonge 